\title{
Evaluation of Carbon and Electron Flow in Lactobacillus brevis as a Potential Host for Heterologous 1-Butanol Biosynthesis
}

\author{
Oksana V. Berezina ${ }^{1^{*}}$, German Jurgens ${ }^{2}$, Natalia V. Zakharova ${ }^{1}$, \\ Rustem S. Shakulov' ${ }^{1}$, Sergey V. Yarotsky ${ }^{1}$, Tom B. Granström ${ }^{2}$ \\ ${ }^{1}$ State Research Institute of Genetics and Selection of Industrial Microorganisms, Moscow, Russian Federation \\ ${ }^{2}$ Department of Biotechnology and Chemical Technology, School of Chemical Technology, Aalto University, Espoo, Finland \\ Email: *mashchenko@yandex.ru
}

Received July 10, 2013; revised August 9, 2013; accepted August 18, 2013

Copyright (C) 2013 Oksana V. Berezina et al. This is an open access article distributed under the Creative Commons Attribution License, which permits unrestricted use, distribution, and reproduction in any medium, provided the original work is properly cited.

\begin{abstract}
Heterofermentative lactic acid bacterium Lactobacillus brevis may be considered as a promising host for heterologous butanol synthesis because of tolerance to butanol and ability to ferment pentose and hexose sugars from wood hydrolysates that are cheap and renewable carbohydrate source. Carbon and electron flow was evaluated in two L. brevis strains in order to assess metabolic potential of these bacteria for heterologous butanol synthesis. Conditions required for generation of acetyl-CoA and NADH which are necessary for butanol biosynthesis have been determined. Key enzymes controlling direction of metabolic fluxes in L. brevis in various redox conditions were defined. In anaerobic glucose fermentation, the carbon flow through acetyl-CoA is regulated by aldehyde dehydrogenase ALDH possessing low affinity to NADH and activity $\left(K_{m}^{\mathrm{NADH}}=200 \mu \mathrm{M}, V_{\max }=0.03 \mathrm{U} / \mathrm{mg}\right.$ of total cell protein). Aerobically, the NADHoxidase $\operatorname{NOX}\left(K_{m}^{\mathrm{NADH}}=25 \mu \mathrm{M}, V_{\max }=1.7 \mathrm{U} / \mathrm{mg}\right)$ efficiently competes with ALDH for NADH that results in formation of acetate instead of acetyl-CoA. In general, external electron acceptors (oxygen, fructose) and pentoses decrease NADH availability for native ethanol and recombinant butanol enzymes and therefore reduce carbon flux through acetyl-CoA. Pyruvate metabolism was studied in order to reveal redirection possibilities of competitive carbon fluxes towards butanol synthesis. The study provides a basis for the rational development of $L$. brevis strains producing butanol from wood hydrolysate.
\end{abstract}

Keywords: Lactobacillus brevis; Metabolism; Carbon and Electron Flow; Heterologous Butanol Synthesis; $\mathrm{SO}_{2}$-Ethanol-Water Hydrolysate

\section{Introduction}

A number of studies have been carried out on the production of liquid fuels from renewable plant sources by microbial synthesis. A special attention is paid to alcohols, mainly ethanol and 1-butanol as an effective substitute for gasoline and diesel in combustion engines [1,2]. 1-butanol has an advantage over ethanol due to its higher energy content, lower volatility, less ignition problems, better miscibility with gasoline and the possibility to use it without modification of engines and infrastructure for supplying and distribution [3]. Anaerobic bacteria of the genus Clostridium are the natural producers of 1-butanol [4]. However, the application of existing Clostridium

"Corresponding author. strains for large scale industry is not feasible in the current economic conditions because of low 1-butanol titer $(<15 \mathrm{~g} / \mathrm{l})$, two-phase metabolism (formation of acids precedes the formation of solvents) hampering organization of a continuous fermentation process, synthesis of a significant amount of by-products (acetone, ethanol, acetate, butyrate) and expensive fermentation substrates.

Several attempts have been made to construct 1-butanol-producing strains based on other microbial platforms such as Escherichia coli, Saccharomyces cerevisiae, Pseudomonas putida, Lactobacillus brevis, Bacillus subtilis [5-10]. A high-titer (30 g/liter) and high-yield ( $70 \%$ to $88 \%$ of the theoretical) production of 1-butanol was achieved in E. coli [11]. This is comparable to or exceeding the levels demonstrated by native producers. 
Economically viable production of biofuels should be based on an inexpensive, renewable raw material like plant biomass. Recently developed SEW ( $\mathrm{SO}_{2}$-ethanolwater) pulping is a promising fractionation process for lignocellulosic biomass. Its advantages over conventional pulping methods include simplified chemical recovery, lower capital costs and rapid impregnation of the feed stocks $[12,13]$. SEW-hydrolysate from spruce chips contains mannose, glucose, galactose, xylose, and arabinose which can be used for microbial fermentation [14]. However, hydrolysis by-products such as formic acid, acetic acid, levulinic acid, furfural and hydroxymethyl furfural inhibit fermentation of many industrial microorganisms, including $E$. coli $[15,16]$.

Heterofermentative lactic acid bacterium Lactobacillus brevis is able to ferment pentose as well as hexose sugars from various plant sources [17] including acid hydrolyzate of hemicellulose [18]. In addition L. brevis is tolerant to $3 \%$ butanol and may be easily adapted to increased butanol concentration $[9,19]$. Thus it can be considered as a potential platform for heterologous butanol synthesis from cheap renewable plant sources. The first objective of the present work is to investigate the ability of wild-type $L$. brevis strains to ferment sugars of SEWhydrolyzate from spruce chips that are abundant waste of woodworking and pulp and paper industry.

In the previous study we constructed a $L$. brevis butanol-producing strain by cloning thl, hbd, crt, bcd, etfB, and etfA genes from Clostridium acetobutylicum [9]. However, the butanol titer in recombinant strain did not exceed $\sim 300 \mathrm{mg} \cdot \mathrm{l}^{-1}$. Expression of the butanol pathway genes did not change the level and the ratio of native $L$. brevis end-products: the spectra of metabolites other than butanol were similar in recombinant and wild-type $L$. brevis strains that indicated the inability of the recombinant pathway to compete with native ones. The present study is focused on evaluation of carbon and electron flow in wild-type $L$. brevis strains in order to assess metabolic potentialities of these bacteria for heterologous butanol synthesis and reveal bottlenecks preventing efficient butanol synthesis by recombinant L. brevis strains.

\section{Materials and Methods}

\subsection{Bacterial Strains and Growth Conditions}

Lactobacillus brevis ATCC 367, Lactobacillus brevis ATCC 8287, and Clostridium acetobutylicum ATCC 824 were used for metabolic studies.

C. acetobutylicum was cultivated anaerobically at $37^{\circ} \mathrm{C}$ in MSS medium as described earlier [20]. L. brevis strains were grown at $30^{\circ} \mathrm{C}$ aerobically (with agitation at $250 \mathrm{rpm}$ ) or semi-anaerobically (without agitation in closed vials) in MRS or HM media supplemented with kanamycin $\left(12.5 \mu \mathrm{g} \cdot \mathrm{ml}^{-1}\right)$. The non-autoclaved MRS medium was composed of $(\mathrm{w} / \mathrm{v}) 1 \%$ casein peptone, $1 \%$ meat extract, $0.5 \%$ yeast extract, $2 \%$ glucose, $0.1 \%$ Tween 80, 0.2\% $\mathrm{K}_{2} \mathrm{HPO}_{4}, 0.5 \%$ Na-acetate, $0.2 \%$ ammonium citrate, $0.02 \% \quad \mathrm{MgSO}_{4} \cdot 7 \mathrm{H}_{2} \mathrm{O}$, and $0.005 \%$ $\mathrm{MnSO}_{4} \cdot \mathrm{H}_{2} \mathrm{O}$. In the autoclaved MRS medium glucose was partly converted to fructose. The HM medium had the same content as the MRS medium except the glucose was substituted with $25 \% \mathrm{SO}_{2}$-ethanol-water hydrolyzate of spruce chips. The SEW-hydrolyzate was kindly provided by E. Sklavounos, Aalto University. Sugar composition of the autoclaved MRS medium and the HM medium was determined by HPLC (Table 1).

\subsection{Analytical Methods}

\subsubsection{Chromatograph}

Metabolic end-products of $L$. brevis were identified and quantified by high-performance liquid chromatography (HPLC). Waters 2695 Separations module was equipped with Waters 2414 Refractive Index Detector, Bio-Rad Aminex HPX-87H column $(300 \mathrm{~mm} \times 7.8 \mathrm{~mm} \times 9 \mu \mathrm{m})$, and Micro-Guard Cation $\mathrm{H}^{+}$-Cartridge (Bio-Rad, Hercules, CA, US). The column was heated at $65^{\circ} \mathrm{C}$; the eluent $\left(5 \mathrm{mM} \mathrm{H}_{2} \mathrm{SO}_{4}\right)$ was circulated at a flow rate of $0.60 \mathrm{~mL} \cdot \mathrm{min}^{-1}$. The sugars were determined by Waters 2690 Separations module with Waters 2414 Refractive Index Detector, equipped with a Bio-Rad HPX-87P column $(300 \mathrm{~mm} \times 7.8 \mathrm{~mm} \times 9 \mu \mathrm{m})$ and two MicroGuard Deashing Cartridges (Bio-Rad, Hercules, CA, US) at $70^{\circ} \mathrm{C}$ with a flow rate of $0.60 \mathrm{~mL} \cdot \mathrm{min}^{-1}$ using deionized water as eluent. Cellobiose (Roth, Karlsruhe, Germany) was added to the samples as an internal standard. Sugar and metabolite concentrations were calculated from at least three experiments, the accuracy was within $\pm 5 \%$.

Table 1. Sugar and uronic acid composition (mM) of MRS and HM media.

\begin{tabular}{ccc}
\hline Sugars & MRS & HM \\
\hline Glucose & 88 & 22 \\
Fructose & 23 & - \\
Xylose & - & 36 \\
Mannose & - & 59 \\
Arabinose & - & 7 \\
Galactose & - & 12 \\
Uronic acids: & & 20 \\
glucuronate, galacturonate \\
and 4-O-Me-glucuronate
\end{tabular}




\subsubsection{Enzyme Assays}

Cell-free extracts were prepared as described previously [9]. The protein content was determined with bicinchoninic acid [21] or by Bradford [22] after removal of the cell debris. Bovine serum albumine (Sigma) was used as a standard.

Lactate dehydrogenase, $\mathrm{NADH}: \mathrm{H}_{2} \mathrm{O}$ oxidase, alcohol dehydrogenase, aldehyde dehydrogenase, and 3-hydroxybutyryl-CoA dehydrogenase activities were measured by NADH oxidation at $340 \mathrm{~nm}\left(\varepsilon_{\mathrm{mM}}^{\mathrm{NADH}}=6.22\right)$ in accordance with the published procedures $[9,23,24]$. ADH activity was measured by $\mathrm{NAD}^{+}$reduction as described by Berezina et al. [9]. All activities were assayed at $30^{\circ} \mathrm{C}$ and $\mathrm{pH} 6.7$ that corresponded to intracellular conditions in logarithmic growth phase [25].

Enzyme activity of pyruvate dehydrogenase was assayed as described by Yahui et al. [26] from the extracts of aerobically or semi-anaerobically grown cells collected at logarithmic growth phase, at pH 7.1 (enzyme optimum) and 6.7 (intracellular $\mathrm{pH}$ ). Pyruvate formate lyase activity was measured as described by Asanuma et al. [27], in an anaerobic chamber. The cell extracts for PFL assay were prepared anaerobically as described by Berezina et al. [9]. Pyruvate oxidase, and pyruvate decarboxylase activities were assayed as described previously [28,29]. One unit of activity was defined as $1 \mu \mathrm{mol}$ of substrate utilized or product formed in a minute per $\mathrm{mg}$ of total cell protein (U/mg).

\subsubsection{Measurement of Intracellular NAD ${ }^{+}$and NADH Levels}

A freshly grown cell culture was concentrated by centrifugation up to $30 \mathrm{mg} \cdot \mathrm{ml}^{-1}$ of total cell protein. For $\mathrm{NAD}^{+}$extraction, $0.1 \mathrm{ml}$ of perchloric acid was mixed with $0.4 \mathrm{ml}$ of cell suspension, incubated for $5 \mathrm{~min}$ at $60^{\circ} \mathrm{C}$ and immediately chilled on ice. The extract was neutralized to $\mathrm{pH} 7.0$ with $0.5 \mathrm{ml}$ of $2 \mathrm{M} \mathrm{KOH}$ containing 1.2 M Tris- $\mathrm{HCl}(\mathrm{pH} 9.0)$ and 1.36 M semicarbazide. The precipitate was removed by centrifugation, and the supernatant was used for $\mathrm{NAD}^{+}$measurements. For NADH extraction, $0.1 \mathrm{ml}$ of $2 \mathrm{M} \mathrm{KOH}$ was mixed with $0.3 \mathrm{ml}$ of cell suspension, incubated for $5 \mathrm{~min}$ at $60^{\circ} \mathrm{C}$ and immediately chilled on ice. The extract was neutralized on ice to $\mathrm{pH} 8.0$ with $0.4 \mathrm{ml}$ of $1 \mathrm{M}$ HEPES, $\mathrm{pH} 5.0$. The precipitate was removed by centrifugation and the supernatant was used for $\mathrm{NADH}$ measurements. $\mathrm{NAD}^{+}$and $\mathrm{NADH}$ concentrations in the extract were determined by enzyme assay with commercial alcohol and lactate dehydrogenases (Sigma-Aldrich) according to Bergmeyer [30]. Absorbance at $340 \mathrm{~nm}$ was measured by a Cintra 404 spectrophotometer. Total intracellular $\left[\mathrm{NAD}^{+}+\right.$ $\mathrm{NADH}]$ and $[\mathrm{NADH}]$ concentrations were calculated assuming that $1 \mathrm{mg}$ of total cell protein binds $3.7 \mu \mathrm{l}$ of cytosole [31].

\section{Results}

\subsection{Effect of Aeration and Sugar Composition on Growth Characteristics of Two L. brevis Strains}

Although L. brevis lacks cytochromes, porphyrins, and respiratory enzymes and is generally recognized as an anaerobic bacteria [32], the aeration positively influenced growth rate of both strains (Figure 1).

In aerobic incubation in MRS medium the ATCC 8287 had a higher growth rate than the ATCC 367, while in semi-anaerobic conditions the difference between the strains was very small (Figure 1(a)).

In HM medium the ATCC 8287 strain had a higher growth rate than the ATCC 367 strain both in aerobic and semi-anaerobic conditions (Figure 1(b)).

Both strains were able to ferment glucose, xylose, arabinose and galactose of SEW-hydrolysate, but not mannose (Figure 2). The 8287 strain fermented xylose better than the 367 strain that correlates with faster growth of the 8287 strain in semi-anaerobic conditions (Figure 1(b)).

In semi-anaerobic fermentation of MRS medium lactate, ethanol and mannitol were produced from glucose and fructose. The level of acetate at first went down, and
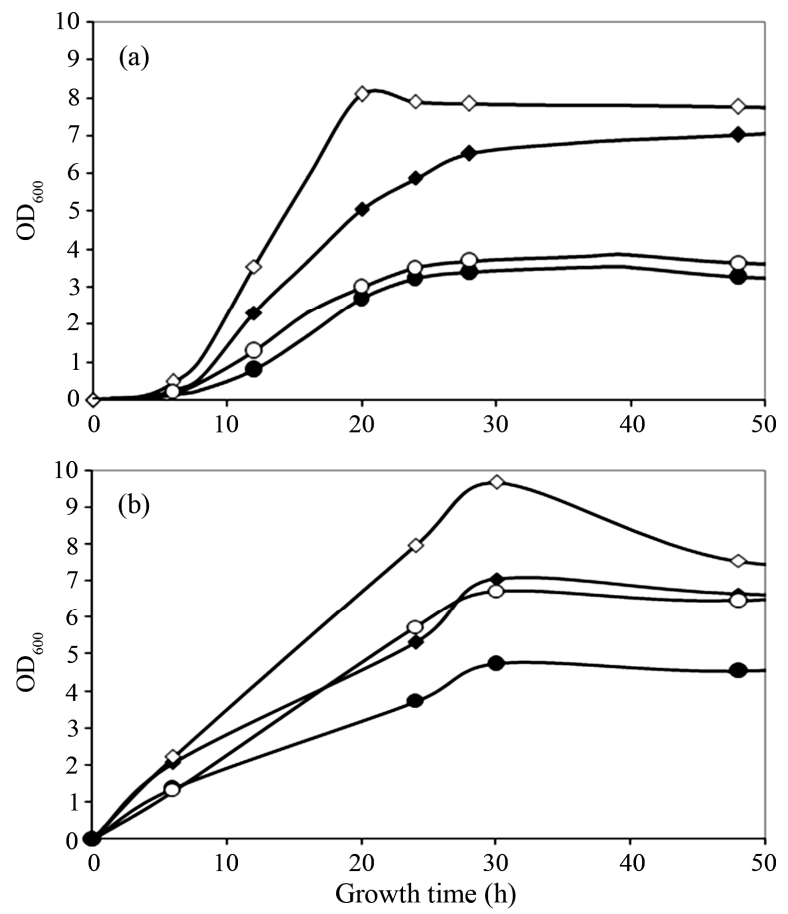

Figure 1. Growth curves of L. brevis ATCC 367 and ATCC 8287 strains on MRS medium (a) and HM medium (b). ( $\bullet$ ): ATCC 367, aerobic growth; $(\diamond)$ : ATCC 8287, aerobic growth; (•): ATCC 367, semi-anaerobic growth; (०): ATCC 8287, semi-anaerobic growth. The mean values calculated from at least three experiments; the accuracy is within $\pm 5 \%$. 


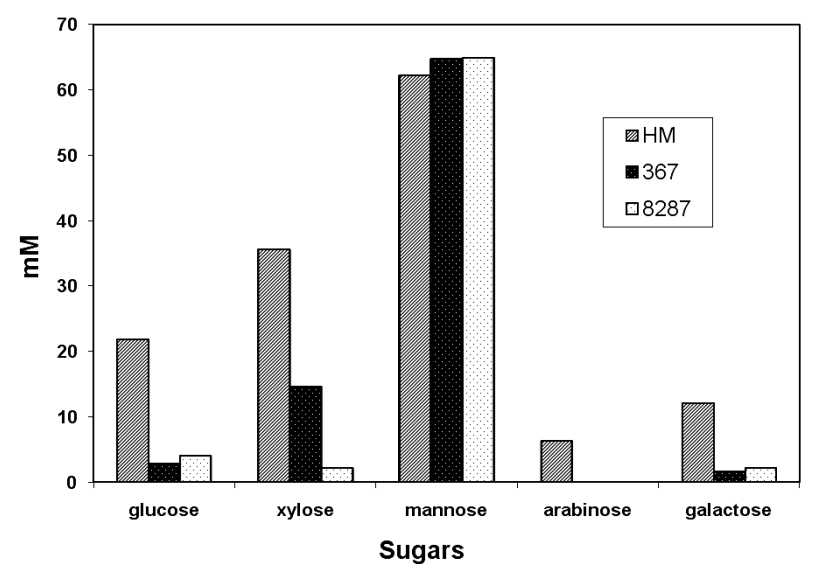

Figure 2. Sugar utilization by L. brevis ATCC 8287 and ATCC 367 strains grown semi-anaerobically on HM medium during $72 \mathrm{~h}$. The mean values of at least three independent experiments are presented.

then came back to initial value (Figure 3(a)). In aerobic MRS fermentation by $L$. brevis 8287 , lactate and acetate were produced in equimolar amounts during exponential growth phase. In stationary growth phase the decrease in lactate concentration was equal to increase in acetate concentration. Ethanol was not produced aerobically and mannitol only in minute amounts (Figure 3(b)). Aerobic and semi-anaerobic fermentations patterns of $L$. brevis 367 were similar to $L$. brevis 8287 .

The time-dependent profiles of sugar utilization and metabolite formation during semi-anaerobic and aerobic fermentation of HM medium containing hexoses, pentoses, and uronic acids (Table 1) by L. brevis 8287 are shown in Figures 3(c) and (d). Lactate, ethanol and acetate were produced semi-anaerobically whereas only lactate and acetate were produced aerobically. In stationary growth phase of aerobic incubation, the concentration of lactate decreased while the acetate concentration increased correspondingly (Figure 3(d)). For L. brevis ATCC 367 the pattern of metabolic end-products was similar. Both strains accumulated biomass in HM medium better than in MRS medium, and the largest difference was observed in semi-anaerobic ATCC 8287 culture (Figure 1).

Fermentation balance of the ATCC 8287 strain cultivated in semi-anaerobic and aerobic conditions on MRS and HM media is shown in Table 2.

\subsection{NADH-Dependent Enzymes of L. brevis Metabolism}

Lactate dehydrogenase (LDH), alcohol dehydrogenase $(\mathrm{ADH})$, aldehyde dehydrogenase (ALDH), and NADH oxidase (NOX) activities were measured in cell extracts of both L. brevis strains. The L. brevis ATCC 367 genome sequence was screened for the corresponding genes (Table 3 ).
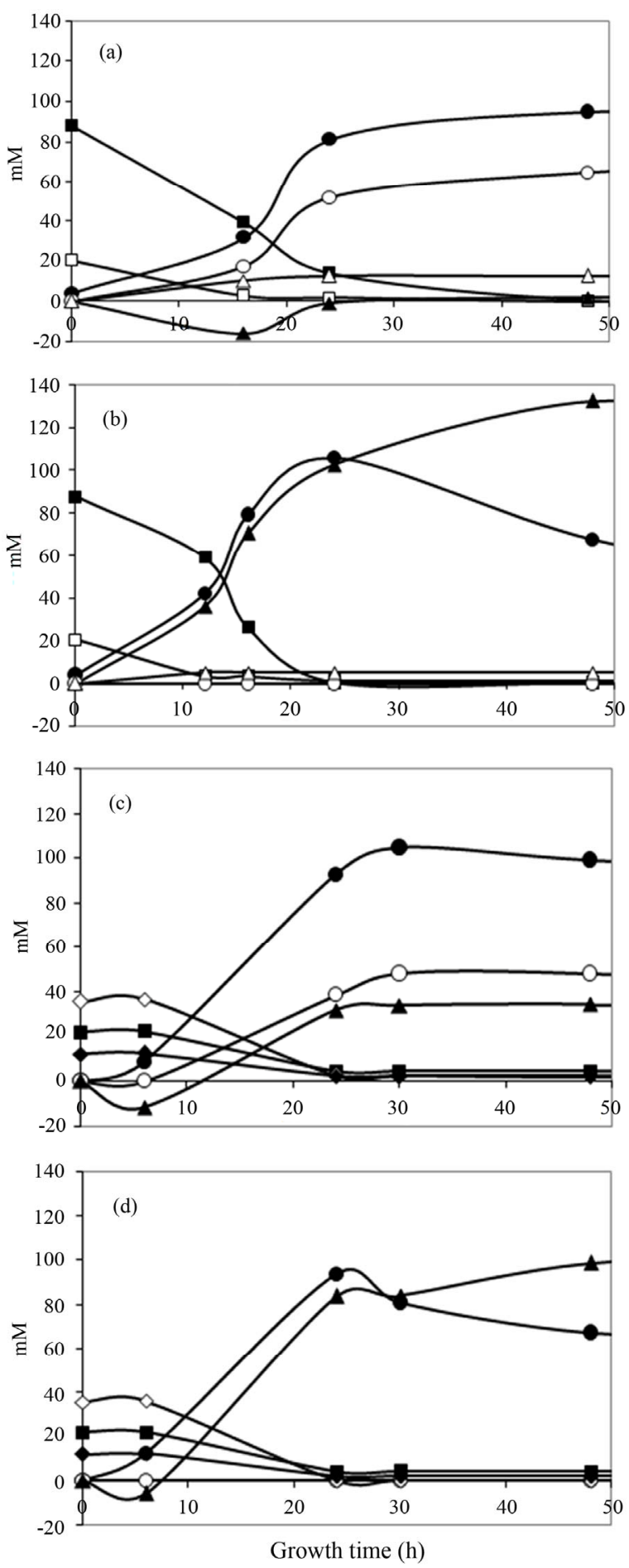

Figure 3. Fermentation patterns of $L$. brevis ATCC 8287 grown semi-anaerobically ((a), (c)) and aerobically ((b), (d)) on MRS medium ((a), (b)) and HM medium ((c), (d)). (a): glucose; $(\square)$ : fructose; $(\bullet)$ : lactate; $(\circ)$ : ethanol; $(\triangle)$ : mannitol; $(\Delta)$ : acetate; $(\diamond)$ : xylose; $(\diamond)$ : galactose. The mean values calculated from at least three experiments. Concentration of acetate produced by $L$. brevis was calculated by subtracting initial acetate concentration $(77 \mathrm{mM}$ and 83 $\mathrm{mM}$ in MRS and HM media correspondingly) from the total amount of acetate in the cultural liquid. 
Table 2. Fermentation balance of $L$. bevis ATCC 8287 cultivated in various redox conditions. The mean values calculated from at least three experiments. The accuracy of measurements is within $\pm 5 \%$.

\begin{tabular}{|c|c|c|c|c|c|c|c|c|}
\hline \multirow{3}{*}{$\begin{array}{c}\text { Fermentable carbohydrate, } \mathrm{mM} \\
\text { Metabolites, } \mathrm{mM}\end{array}$} & \multicolumn{4}{|c|}{ MRS } & \multicolumn{4}{|c|}{ HM } \\
\hline & \multicolumn{4}{|c|}{ Sugars $(111)=$ glucose $(88)+$ fructose $(23)$} & \multicolumn{4}{|c|}{ Sugars $(77)=$ hexoses $(34)+$ pentoses $(43)$, uronic acids $(20)$} \\
\hline & Lactate & Acetate & Ethanol & Mannitol & Lactate & Acetate & Ethanol & Mannitol \\
\hline Cultivation time, $\mathrm{h}$ & \multicolumn{8}{|c|}{ Semi-anaerobic cultivation } \\
\hline 30 & 87 & - & 59 & 13 & 105 & 34 & 48 & - \\
\hline 48 & 93 & 3 & 71 & 13 & 99 & 34 & 48 & - \\
\hline Cultivation time, $\mathrm{h}$ & \multicolumn{8}{|c|}{ Aerobic cultivation } \\
\hline 24 & 106 & 103 & - & 5 & 94 & 84 & - & - \\
\hline 48 & 68 & 133 & - & 5 & 68 & 99 & - & - \\
\hline
\end{tabular}

Table 3. L. brevis genes presumably encoding enzymes involved in pyruvate and acetyl-CoA metabolism.

\begin{tabular}{ccc}
\hline Gene & Predicted enzyme & EC number \\
\hline LVIS 0514 & NAD $^{+}$-dependent L-lactate dehydrogenase L-LDH & 1.1 .1 .27 \\
LVIS 1352 & NAD $^{+}$-dependent D-lactate dehydrogenase D-LDH & 1.1 .1 .28 \\
LVIS 0119 & Bifunctional acetaldehyde-CoA/ & 1.2 .1 .10 \\
LVIS 0254, & Alcohol dehydrogenase ALDH, ADH & 1.1 .1 .1 \\
LVIS 1019 & Zn-dependent alcohol dehydrogenases ADH & 1.1 .1 .1 \\
LVIS 1558 & NADH-oxidase NOX & 1.6 .99 .3 \\
LVIS 0313 & Pyruvate oxidase POX & 1.2 .3 .3 \\
LVIS 1407, & Pyruvate dehydrogenase enzyme complex PDH: & \\
LVIS 1408, & Dihydrolipoamide dehydrogenase, & 1.8 .1 .4 \\
LVIS 1409, & Dihydrolipoamide succinyltransferase (the E2 component of PDH complex) & 2.3 .1 .12 \\
LVIS 1410 & Beta and alpha subunits for E1 component of PDH complex, correspondingly & 1.2 .4 .1 \\
LVIS 0491 & Acetolactate synthase ALS & 2.2 .1 .6 \\
LVIS 0492 & Acetolactate decarboxylase ALDB & 4.1 .1 .5 \\
LVIS 0187 & Acetoin reductase BUTB & 1.1 .1 .4 \\
LVIS 2218 & Acetyl-CoA C-acetyltransferase (thiolase) THL & 2.3 .1 .9
\end{tabular}

*By analysis of L. brevis ATCC 367 genome, GenBank (CP000416), [33,34].

Overall lactate dehydrogenase activity was higher than the other detected enzyme activities: $V_{\max } 37.0$ and 26.5 $\mathrm{U} / \mathrm{mg}$ of total cell protein in the 367 and 8287 strains correspondingly. ALDH activity was 0.02 and $0.03 \mathrm{U} / \mathrm{mg}$ in 367 and 8287 strains correspondingly (Table 4). ADH activity following the ALDH in the ethanol-forming pathway was $10.8 \mathrm{U} / \mathrm{mg}$ in both strains. No reverse ADH activity was detected in cell extracts at $\mathrm{pH} 6.7$ or $\mathrm{pH} 6.3$. This indicates that the process of ethanol formation is irreversible in physiological conditions. $K_{m}^{\mathrm{NADH}}$ values for LDH and ALDH were comparable and about $2-2.5$ times higher than $K_{m}^{\mathrm{NADH}}$ of ADH (Table 4). NOX has higher activity compared to ALDH and the highest affinity to NADH among all the tested enzymes: $V_{\max }$ (NOX) $=1.7 \mathrm{U} / \mathrm{mg}, K_{m}(\mathrm{NOX})=25 \mu \mathrm{M}$ versus $V_{\max }(\mathrm{ALDH})=$ $0.03 \mathrm{U} / \mathrm{mg}, K_{m}(\mathrm{ALDH})=200 \mu \mathrm{M}$ for ATCC 8287 strain (Table 4).
In the recombinant butanol-producing $L$. brevis strains [7], the 3-hydroxybutyryl-CoA dehydrogenase (HBD, EC 1.1.1.35) is the first NADH-dependent enzyme of the heterologous butanol pathway originated from acetylCoA. The $K_{m}^{\mathrm{NADH}}$ of HBD is $178 \mu \mathrm{M}$, which is slightly lower than $K_{m}^{\mathrm{NADH}}$ of ALDH but sufficiently higher than $K_{m}^{\mathrm{NADH}}$ of NOX (Table 4).

Intracellular $\mathrm{NAD}^{+} / \mathrm{NADH}$ ratio and total $\left[\mathrm{NAD}^{+}+\right.$ $\mathrm{NADH}$ ] concentration as a function of cell growth were determined for batch cultures (Figure 4).

\subsection{Pyruvate-Converting Pathways in L. brevis}

In L. brevis, pyruvate is converted to D- and L-lactate by corresponding lactate-dehydrogenases [9] (Table 3). But under certain conditions LAB may use alternative ways of utilizing pyruvate than reduction to lactic acid. 
Table 4. $K_{m}^{\mathrm{NADH}}(\mu \mathrm{M})$ and $V_{\max }\left(\mathrm{U} \cdot \mathrm{mg}^{-1}\right.$ of total cell protein $)$ for NADH-dependent enzymes of $L$. brevis ATCC367, $L$. brevis ATCC8287 and HBD of C. acetobutylicum ATCC824. The mean values calculated from at least three experiments, the accuracy is within $\pm 10 \%$.

\begin{tabular}{|c|c|c|}
\hline Enzyme & $K_{m}^{\mathrm{NADH}}, 367 / 8287$ & $\mathrm{~V}_{\max }, 367 / 8287$ \\
\hline \multicolumn{3}{|c|}{ L. brevis ATCC $367 / 8287$} \\
\hline LDH & $201 / 220$ & $37 / 26.5$ \\
\hline ALDH & $204 / 200$ & $0.02 / 0.03$ \\
\hline $\mathrm{ADH}$ & $82 / 108$ & $10.8 / 10.8$ \\
\hline NOX & $23 / 25$ & $0.2 / 1.7$ \\
\hline \multicolumn{3}{|c|}{ C. acetobutylicum ATCC 824} \\
\hline HBD & 178 & 5.9 \\
\hline
\end{tabular}

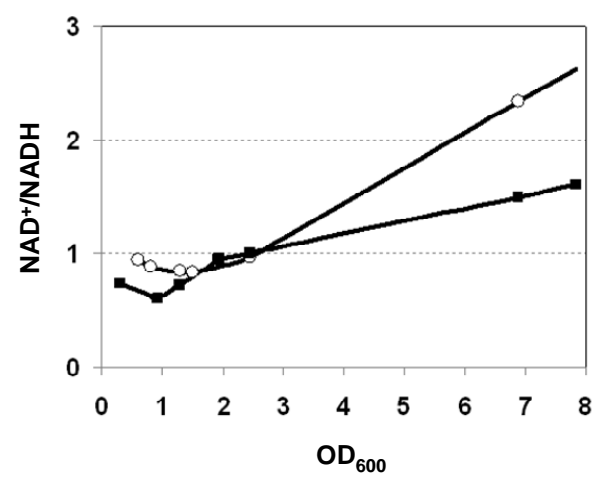

(a)

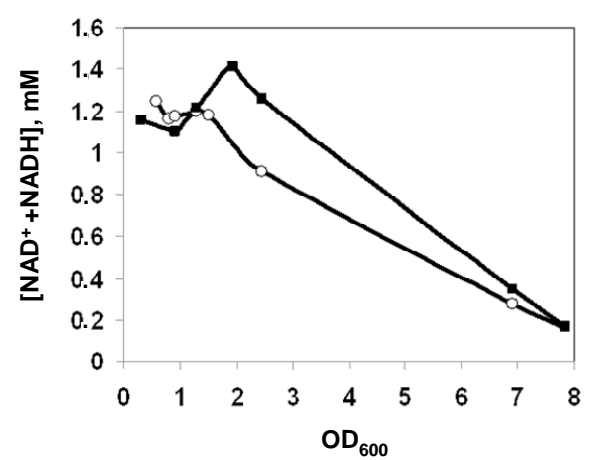

(b)

Figure 4. Intracellular $\mathrm{NAD}^{+} / \mathrm{NADH}$ ratio (A) and total $\left[\mathrm{NAD}^{+}+\mathrm{NADH}\right]$ concentrations $(\mathrm{B})$ in $L$. brevis ATCC 8287 ( $\circ$ ) and $L$. brevis ATCC 367 (घ) strains grown on MRS medium. The mean values calculated from at least three experiments. The accuracy of measurements is within $\pm 10 \%$.

Pathways of pyruvate metabolism were investigated in L. brevis ATCC 367 and 8287 strains (Figure 5). Pyruvate oxidase (POX), pyruvate decarboxylase (PDC), pyruvate dehydrogenase (PDH) and pyruvate formate lyase (PFL) activities were assayed in the cell extracts. The $L$. brevis ATCC 367 genome was screened for the corresponding genes.

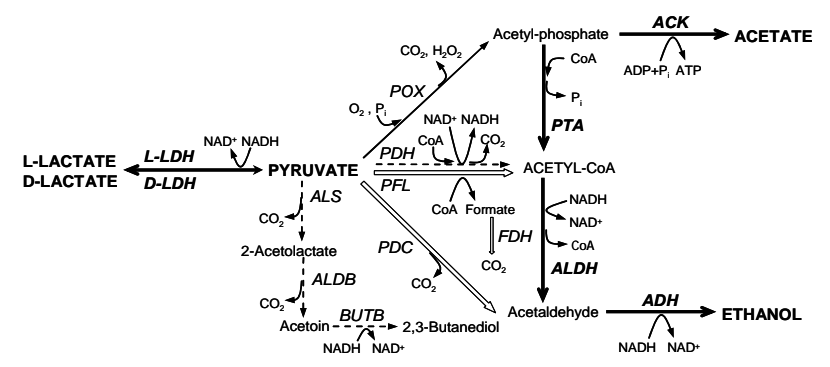

Figure 5. Metabolism of pyruvate in $L$. brevis. The solid arrows indicate active pathways. The dotted arrows- the enzymes are not active, but the putative genes are predicted in $L$. brevis genome. The hollow arrows-neither gene nor enzyme activity or metabolic product were found. L-LDH: L-lactate dehydrogenase, D-LDH: D-lactate dehydrogenase, ADH: alcohol dehydrogenase, ALDH: aldehyde dehydrogenase, PTA: phosphotransacetylase, ACK: acetate kinase, PDH: pyruvate dehydrogenase, PFL: pyruvate formate lyase, PDC: pyruvate decarboxylase, POX: pyruvate oxidase, FDH: formate dehydrogenase, ALS: acetolactate syntase, ALDB: alpha-acetolactate decarboxylase, BUTB: diacetyl acetoin reductase (butanediol dehydrogenase).

Pyruvate oxidase activity was detectable only at the late stationary phase in aerobic conditions being 0.02 and $0.01 \mathrm{U} / \mathrm{mg}$ of total cell protein for ATCC 8287 and ATCC 367 strains respectively. The putative pyruvate oxidase-encoding gene was identified in the $L$. brevis ATCC 367 genome (Table 3).

Although PDH activity was not detected, the genes predictably encoding enzymes of PDH complex were identified in L. brevis ATCC 367 genome (Table 3). No PFL (EC 2.3.1.54) or PDC (EC 4.1.1.1) activities were detected under conditions applied, and the corresponding genes were not identified during genome analysis. Formate produced in the PFL reaction was not found among metabolic end-products.

The genes presumably encoding acetolactate synthase (ALS), alpha-acetolactate decarboxylase (ALDB) and diacetyl acetoin reductase also named butanediol dehydrogenase (BUTB) participating in synthesis of acetolactate, acetoin and 2,3-butenediol from pyruvate, were identified in L. brevis ATCC 367 genome (Table 3). However, these metabolites were not detected in cultural liquid during $L$. brevis semi-anaerobic or aerobic fermentation in MRS or HM media.

Thus, besides conversion into lactate, pyruvate may be converted into acetyl-phosphate by pyruvate oxidase in strictly aerobic conditions and under glucose limitation. No other overlaps between lactate and ethanol metabolic branches have been detected in L. brevis.

Data of metabolic stoichiometry and enzyme kinetics allowed developing the scheme of carbon and electron flow in $L$. brevis in anaerobic and aerobic glucose fermentation (Figure 6). 


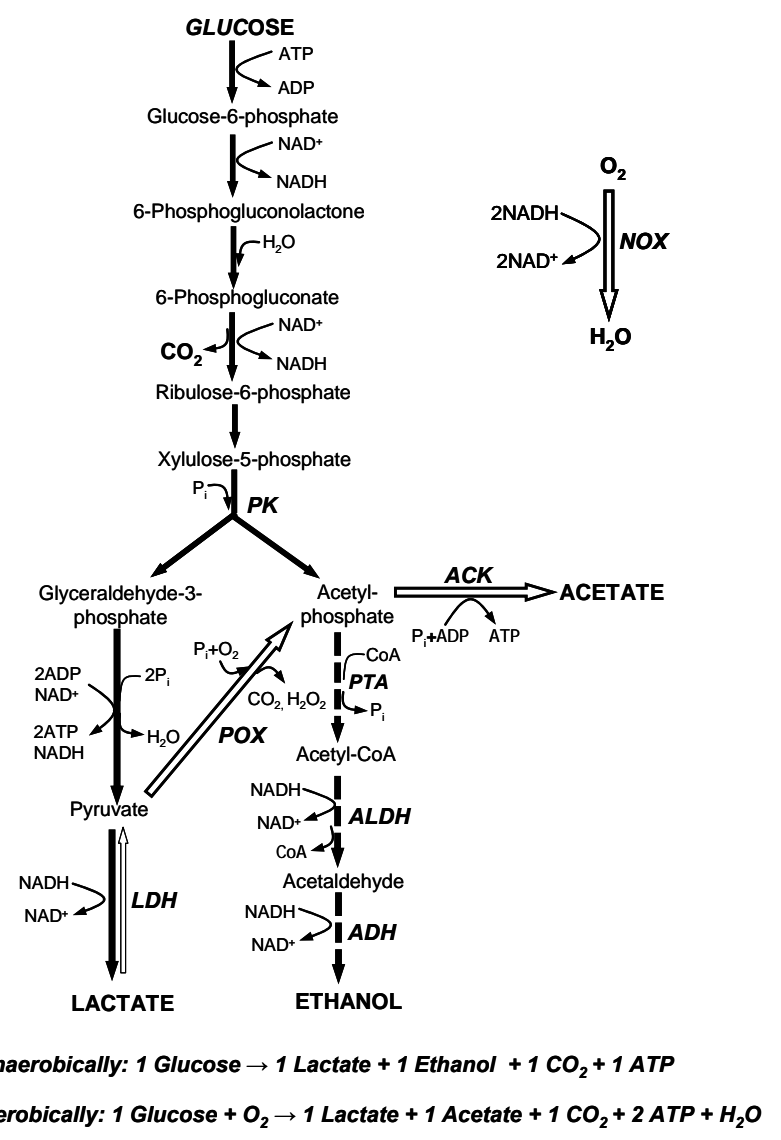

Figure 6. The scheme of carbon and electron flow in $L$. brevis in anaerobic and aerobic glucose fermentation. The solid arrows indicate native permanently acting reactions. The dotted arrows indicate reactions acting preferably in anaerobic condition. The hollow arrows indicate reactions active aerobically. NOX: NADH oxydase, LDH: lactate dehydrogenase, ADH: alcohol dehydrogenase, ALDH: aldehyde dehydrogenase, PK: phosphoketolase, PTA: phosphotransacetylase, ACK: acetate kinase, POX: pyruvate oxidase.

\section{Discussion}

\subsection{Key Factors Influencing the Direction of Carbon and Electron Flow in L. brevis}

L. brevis metabolism is based on carbohydrate fermentation coupled with substrate level phosphorylation. Oxidation of a substrate leads to formation of NADH from $\mathrm{NAD}^{+}$, which has to be regenerated continuously. Stoichiometry analysis of fermentation in various redox conditions (Table 2) proved that $L$. brevis utilizes sugars through the 6-phosphogluconate (6-PG) pathway. The crucial enzyme of the 6-PG pathway is phosphoketolase, which converts xylulose-5-phosphate (C5) into glyceraldehyde-3-phosphate (C3) and acetyl phosphate (C2) [32] (Figure 6). In semi-anaerobic glucose fermentation this bifurcation leads to formation of lactate (C3) and ethanol (C2) (Table 2, Figure 3(a)) that have a key role in $\mathrm{NAD}^{+}$ regeneration.
In comparison with the lactate branch, the NADHoxidizing capacity of the ethanol branch is very low: ALDH activity was about three orders lower than LDH activity (Table 4). It makes ALDH the bottleneck of the L. brevis anaerobic metabolism, despite the highly active ADH following the ALDH in the ethanol-forming pathway. The ethanol branch does not bring additional ATP to the cells and it participates only in the maintenance of red-ox balance that determines the low level of biomass accumulation by $L$. brevis grown semi-anaerobically in MRS medium (Figure 1(a)).

In aerobic conversion of hexoses, the oxygen acts as the external electron acceptor in a reaction catalyzed by $\mathrm{NADH}: \mathrm{H}_{2} \mathrm{O}$ oxidase (NOX) (Figure 6). Due to significantly higher activity and affinity to NADH compared to ALDH (Table 4), the NOX has the strong benefit of $\mathrm{NAD}^{+}$regeneration and thereby prevents ethanol formation. The acetyl-phosphate is completely redirected from acetyl-CoA formation towards the acetate formation (Figure 3(b)) accompanied by synthesis additional ATP in acetate kinase reaction (Figure 6), and hence faster aerobic growth is observed in comparison to semi-anaerobic conditions (Figure 1(a)).

The rapid growth of ATCC 8287 versus ATCC 367 in MRS medium in aerobic conditions (Figure 1(a)) was obviously dependent on higher NOX activity of the ATCC 8287 strain: $1.7 \mathrm{U} / \mathrm{mg}$ in ATCC 8287 vs 0.20 $\mathrm{U} / \mathrm{mg}$ in ATCC 367 (Table 4).

In the recombinant $L$. brevis strains the native ethanol and recombinant butanol pathways originate from acetylCoA [9]. 3-Hydroxybutyryl-CoA dehydrogenase (HBD) is a first NADH-dependent enzyme of the butanol pathway. In aerobic conditions, the NOX, because of its comparatively high activity and affinity to NADH, efficiently competed for reducing equivalents not only with the ALDH, but with the HBD: the affinity towards NADH of the HBD was about 7 times lower than the NOX affinity (Table 4). For this reason, the redirection of the electron and carbon flow towards butanol synthesis was not achieved aerobically, and the recombinant $L$. brevis strains produced butanol only in semi-anaerobic fermentation during exponential growth phase [9].

An active role of oxygen and NOX in growth and energy metabolism of various LAB species has been demonstrated in previous studies [35-37]. For example it was shown that the growth rate and the $\mathrm{Y}_{\mathrm{glc}}$ of Leuconostoc $\mathrm{sp}$ in aerated cultures were higher compared to non-aerated. An NOX-deficient mutant did not shift from ethanol to acetate production, and $\mathrm{Y}_{\text {glc }}$ was the same aerobically and anaerobically [37].

The ratio of $\mathrm{NAD}^{+} / \mathrm{NADH}$ and total intracellular $\left[\mathrm{NAD}^{+}+\mathrm{NADH}\right]$ concentration correlated with the sugar consumption and influenced the pathway fluxes at the level of various dehydrogenase reactions. In the loga- 
rithmic growth phase of a batch culture, the $\mathrm{NAD}^{+} /$ $\mathrm{NADH}$ ratio increased (Figure 4(a)) while total $\left[\mathrm{NAD}^{+}+\right.$ $\mathrm{NADH}$ ] concentration decreased (Figure 4(b)). The intracellular NADH concentration dropped from 700 to 50 $\mu \mathrm{M}$ consequently passing through the $K_{m}$ values of $\mathrm{LDH}$, ALDH, ADH, and hence the activity of the corresponding enzymes decreased. In this way the cell automatically regulates carbon fluxes in response to environmental conditions.

\subsection{Fermentation of Complex Sugar Substrates}

Anaerobic heterolactic fermentation of 1 mole glucose through 6-PG pathway gives theoretically 1 mole of lactic acid, ethanol, $\mathrm{CO}_{2}$ and ATP. Semi-anaerobic incubation of L. brevis in MRS media supplemented with glucose resulted in almost theoretical distribution of lactate and ethanol [9].

A complex fermentation medium changes the balance and the composition of end-products. Lactate, ethanol, acetate and mannitol were produced during semi-anaerobic fermentation of MRS medium containing glucose and fructose (Figure 3(a), Table 2). Mannitol formation indicates that fructose is not only used as a carbon source, but as an additional electron acceptor, and metabolic intensity prevails over efficiency of substrate utilization. Reduction of fructose to mannitol may be catalyzed by $\mathrm{NAD}^{+}$: mannitol dehydrogenase that is presumably encoded in L. brevis ATCC 367 by LVIS 2162 gene. This reaction allows overcoming the low capacity of the ethanol branch for $\mathrm{NAD}^{+}$regeneration arising at the level of aldehyde dehydrogenase [38]. Using the mannitol pathway in fructose fermentation was earlier described with Oenococcus oeni [39].

In aerobic conditions NOX prevented not only the ethanol formation, but also the use of fructose as an electron acceptor (Figure 3(b), Table 2).

L. brevis strains can utilize hexoses (glucose, galactose), pentoses (xylose, arabinose) and uronic acids of SEW-hydrolyzate (Figure 2, Table 2). $\mathrm{No}^{\mathrm{CO}_{2}}$ is formed during pentose fermentation in 6-PG pathway and since no dehydrogenation steps are necessary to reach the $\mathrm{xy}-$ lulose-5-phosphate. Consequently the ethanol formation becomes redundant. Instead, acetyl phosphate is used by the acetate kinase yielding acetate and ATP. Fermentation of pentoses thus leads to production of equimolar amounts of lactic and acetic acids [32]. Therefore fermentation of HM medium resulted in lower ethanol and higher acetate ratio as well as higher biomass accumulation level compared to MRS medium containing glucose and fructose (Table 2). The uronic acids present in SEWhydrolyzate may be utilized to form lactate and acetate (http://www.genome.jp/kegg-bin/show_pathway?lbr0004 $0)$.

\subsection{Role of Pyruvate Oxidase in L. brevis Metabolism}

Under aerobic conditions and sugar limitation acetate is produced at the expense of lactate as glucose becomes depleted and $L$. brevis enters the stationary phase of growth (Figures 3(b) and (d)). Various LAB species can use lactate as a carbon source $[40,41]$. The pathway of lactate to acetate conversion could be performed via three enzymatic steps: oxidation of lactate to pyruvate by the NADH-dependent D- and L-LDHs, oxidative decarboxylation of pyruvate to acetyl-phosphate by pyruvate oxidase, and dephosphorylation of acetyl-phosphate to acetate by acetate kinase (Figures 5, 6). ATP formed in ACK reaction provides the cells with energy in the stationary phase. The LDH-POX-ACK pathway is regulated at the level of pyruvate-oxidase activity, which is induced by $\mathrm{O}_{2}$ and repressed by glucose [41-45]. In the $L$. brevis ATCC 367 genome, the putative pyruvate oxidase-encoding gene was identified. The pyruvate oxidase activity was detected at the late stationary phase of aerobic growth. Lactate to acetate conversion could also be performed aerobically by oxygen-dependent lactate oxidase (lactate 2-mono-oxygenase). However, no similarity with the corresponding genes was found in $L$. brevis genome analysis.

Thereby in aerobic conditions and under glucose limitation $L$. brevis cells may use pyruvate oxidase as a link between pyruvate and acetyl-phosphate in a pathway from lactate to acetate. Since anaerobic conditions are required for heterologous butanol synthesis, the aerobically active pyruvate oxidase cannot be used for redirecting carbon flux from lactate to butanol synthesis.

\subsection{Proposed Strategy for Redirection L. brevis Carbon and Electron Flow towards Butanol Synthesis}

In recombinant butanol-producing $L$. brevis strains, acetyl-CoA is the butanol precursor; the reducing equivalents are necessary for enzymes of heterologous butanol pathway. Metabolic study suggests that in L. brevis the acetyl-CoA is formed from acetyl-phosphate in anaerobic glucose fermentation, i.e. in conditions where NADHoxidase is inactive and NADH equivalents are available for the enzymes of ethanol biosynthesis. Thus anaerobic conditions are required for heterologous butanol synthesis. Semi-aerobic cultivation is possible too because oxygen availability in the beginning of fermentation meets the energetic needs of cells allowing intensive growth. Presence of pentoses, uronic acids and external electron acceptors other to oxygen (e.g. fructose) in fermentation medium enhances cells growth but unfavorable for butanol synthesis.

Inactivation of the LDHs could not only shut off the 
competitive carbon flux, but it could partly compensate NADH-deficiency of butanol pathway by saving 1 mole NADH per $1 \mathrm{~mol}$ of butanol. The surplus of pyruvate should be redirected toward butanol synthesis. However, enzymes converting pyruvate into acetyl-CoA in anaerobic conditions have not been detected in L. brevis. Therefore pyruvate redirection may be organized by cloning the pyruvate formate lyase genes (Figure 7).

The anaerobically active PFL enzyme system has been shown to be operational in several LAB species [46-48]. Cloning the formate dehydrogenase (FDH) might help to utilize formate produced in PFL reaction and provide an additional mole of NADH per mol of 1-butanol produced (Figure 7).

Despite the principal possibility to support the butanol synthesis [9], the native L. brevis ALDH, ADH and THL, and recombinant clostridial $\mathrm{BCD} / \mathrm{Etf} \mathrm{AB}$ cannot provide a high capacity pathway for butanol because of 1) low activity of ALDH and THL, 2) low specificity towards C4 substrate of ALDH and ADH [9] and 3) cofactor (FAD and ferredoxin) deficiency for BCD/EtfAB [49]. These enzymes should be enhanced or substituted with efficient analogues.

\section{Conclusions}

Carbon and electron flow was investigated in two L. bre-

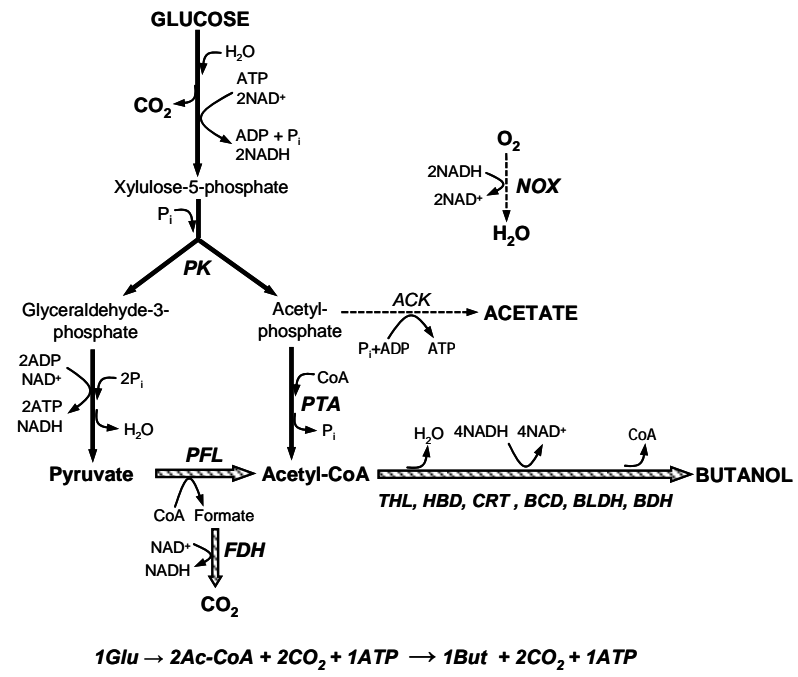

Figure 7. Possible ways for rerouting carbon and electron flow towards butanol synthesis. Semi-anaerobic conditions are required for cultivation. The solid arrows indicate native permanently acting reactions. The dotted arrows indicate reactions acting in presence of oxygen. The hatched arrows indicate reactions providing heterologous butanol synthesis. THL: thiolase, BLDH: butanol dehydrogenase, BLDH: butyraldehyde dehydrogenase, BCD: butyryl-CoA dehydrogenase, CRT: crotonase, HBD: 3-hydroxybutyryl-CoA dehydrogenase, LDH: lactate dehydrogenase, NOX: NADH oxidase, PK: phosphoketolase, PTA: phosphotransacetylase, PFL: pyruvate formate lyase, FDH: formate dehydrogenase, ACK: acetate kinase. vis strains in order to assess metabolic potential of these bacteria for heterologous butanol synthesis. The study approach was based on analysis of fermentation stoichiometry in various redox conditions together with catalytic properties $\left(K_{m}^{\mathrm{NADH}}, V_{\max }\right)$ of the NADH-dependent enzymes from the main metabolic pathways.

Conditions necessary for generation of acetyl-CoA and NADH required for butanol biosynthesis have been determined. Key enzymes controlling direction of carbon and electron flow in L. brevis were defined.

In anaerobic glucose fermentation, the carbon flow through acetyl-CoA and the slow $\mathrm{NAD}^{+}$regeneration rate are controlled by aldehyde dehydrogenase ALDH $\left(K_{m}^{\mathrm{NADH}}=200 \mu \mathrm{M}, V_{\max }=0.03 \mathrm{U} / \mathrm{mg}\right)$. Aerobically, the NOX, due to its comparatively high affinity to NADH and activity $\left(K_{m}^{\mathrm{NADH}}=25 \mu \mathrm{M}, V_{\max }=1.7 \mathrm{U} / \mathrm{mg}\right)$, efficiently competes with ALDH for NADH that results in redirecting carbon flow from acetyl-CoA towards acetate formation.

In recombinant butanol-producing strains the enzymes of the native ethanol and heterologous butanol pathways compete for acetyl-CoA and NADH. Aerobically, the NOX, because of low $K_{m}^{\mathrm{NADH}}$, prevents not only the ethanol but also the butanol formation.

In general, availability of external electron acceptors (oxygen, fructose) enhances biomass accumulation associated with additional ATP synthesis in acetate kinase reaction, but reduces NADH availability for enzymes of ethanol pathway and, therefore, decreases carbon flux through acetyl-CoA.

Pyruvate metabolism was investigated to find redirection possibilities of competitive carbon fluxes towards butanol synthesis. Pyruvate may be converted into acetyl-phosphate by pyruvate oxidase in strictly aerobic conditions and under glucose limitation. No other overlaps between lactate and ethanol metabolic branches have been detected in L. brevis.

L. brevis strains ferment glucose, galactose, arabinose, and xylose from SEW-hydrolysate of spruce chips, but not utilize mannose. Increased acetate formation accompanied by enhanced cell growth and decreased ethanol synthesis indicated reduced carbon flow though the acetylCoA. Thus, SEW-hydrolyzate could be used for initial biomass accumulation of butanol-producing $L$. brevis strains. Using SEW-hydrolysate for butanol synthesis requires optimization of fermentation media in order to increase NADH availability for enzymes of butanol pathway.

The study provides a basis for rational development of L. brevis strains producing butanol from SEW-hydrolysate and proposes possible engineering ways for rerouting carbon and electron flow towards butanol synthesis.

\section{Acknowledgements}

This work has been supported in part by the Ministry of 
Education and Science of the Russian Federation (EurAsES program, contract № 16.M04.12.0017) and by Academy of Finland (grant № 137469, 15.04.2010 applied by Tom Granström). We are most grateful to Professor Matti Leisola, Aalto University, School of Chemical Technology, for his invaluable advice and helpful discussions.

\section{REFERENCES}

[1] D. Antoni, V. V. Zverlov and W. H. Schwarz, "Biofuels from Microbes," Applied Microbiology and Biotechnology, Vol. 77, No. 1, 2007, pp. 23-35. doi:10.1007/s00253-007-1163-x

[2] C. Jin, M. Yao, H. Liu, F. Chia-fon, C. F. Lee and J. Ji, "Progress in the Production and Application of n-Butanol as a Biofuel," Renewable and Sustainable Energy Reviews, Vol. 15, No. 8, 2011, pp. 4080-4106. doi:10.1016/j.rser.2011.06.001

[3] H. Li, A. F. Cann and J. C. Liao, "Biofuels: Biomolecular Engineering Fundamentals and Advances," Annual Review of Chemical and Biomolecular Engineering, Vol. 1, 2010, pp. 19-36.

[4] E. McCoy, E. B. Fred, W. H. Peterson and E. G. Hastings, "A Cultural Study of the Acetone Butyl Alcohol Organism," The Journal of Infectious Diseases, Vol. 39, No. 6, 1926, pp. 457-483. doi:10.1093/infdis/39.6.457

[5] S. Atsumi, A. F. Cann, M. R. Connor, C. R. Shen, K. M. Smith, M. P. Brynildsen, K. J. Chou, T. Hanai and J. C. Liao, "Metabolic Engineering of Escherichia coli for 1Butanol Production," Metabolic Engineering, Vol. 10, No. 6, 2008, pp. 305-311. doi:10.1016/j.ymben.2007.08.003

[6] M. Inui, M. Suda, S. Kimura, K. Yasuda, H. Suzuki, H. Toda, S. Yamamoto, S. Okino, N. Suzuki and H. Yukawa, "Expression of Clostridium acetobutylicum Butanol Synthetic Genes in Escherichia coli," Applied Microbiology and Biotechnology, Vol. 77, No. 6, 2008, pp. 1305-1316. doi:10.1007/s00253-007-1257-5

[7] E. J. Steen, R. Chan, N. Prasad, S. Myers, C. J. Petzold, A. Redding, M. Ouellet and J. D. Keasling, "Metabolic Engineering of Saccharomyces cerevisiae for the Production of n-Butanol," Microbial Cell Factories, Vol. 3, 2008, pp. 7-36.

[8] D. R. Nielsen, E. Leonard, S.-H. Yoon, H.-C. Tseng, C. Yuan and K. L. J. Prather, "Engineering Alternative Butanol Production Platforms in Heterologous Bacteria," Metabolic Engineering, Vol. 11, No. 4-5, 2009, pp. 262273. doi:10.1016/j.ymben.2009.05.003

[9] O. V. Berezina, N. V. Zakharova, A. Brandt, S. V. Yarotsky, W. H. Schwarz and V. V. Zverlov, "Reconstructing the Clostridial n-Butanol Metabolic Pathway in Lactobacillus brevis," Applied Microbiology and Biotechnology, Vol. 87, No. 2, 2010, pp. 635-646. doi: $10.1007 / \mathrm{s} 00253-010-2480-\mathrm{z}$

[10] B. B. Bond-Watts, R. J. Bellerose and M. C. Y Chang, "Enzyme Mechanism as a Kinetic Control Element for Designing Synthetic Biofuel Pathways," Nature Chemical Biology, Vol. 7, No. 4, 2011, pp. 222-227. doi:10.1038/nchembio. 537

[11] C. R. Shen, E. I. Lan, Y. Dekishima, A. Baez, K. M. Cho and J. C. Liao, "Driving Forces Enable High-titer Anaerobic 1-Butanol Synthesis in Escherichia coli," Applied and Environmental Microbiology, Vol. 77, No. 14, 2011, pp. 2905-2915. doi:10.1128/AEM.03034-10

[12] M. Rakkolainen, M. Iakovlev, A.-L. Teräsvuori, E. Sklavounos, G. Jurgens, T. B. Granström and A. van Heiningen, " $\mathrm{SO}_{2}$-Ethanol-Water Fractinations of Forest Biomass and Implications for Biofuel Production by ABE Fermentation," Cellulose Chemistry and Technology, Vol. 44, No. 4-6, 2010, pp. 139-145.

[13] E. Sklavounos, M. Iakovlev, M. Rakkolainen, A. L. Teräsvuori, G. Jurgens, T. Granström and A. van Heiningen, "Conditioning of $\mathrm{SO}_{2}$-Ethanol-Water Spent Liquor from Spruce for the Production of Chemicals by ABE Fermentation," Holzforschung, Vol. 65, No. 4, 2011, pp. 551558. doi:10.1515/hf.2011.103

[14] S. A. Survase, E. Sklavounos, G. Jurgens, A. van Heiningen and T. Granström, "Continuous Acetone-ButanolEthanol Fermentation Using $\mathrm{SO}_{2}$-Ethanol-Water Spent Liquor from Spruce," Bioresource Technology, Vol. 102, No. 23, 2011, pp. 10996-11002. doi:10.1016/j.biortech.2011.09.034

[15] E. N. Miller, L. R. Jarboe, P. C. Turner, P. Pharkya, L. P. Yomano, S. W. York, D. Nunn, K. T. Shanmugam and L. O. Ingram, "Furfural Inhibits Growth by Limiting Sulfur Assimilation in Ethanologenic Escherichia coli Strain LY180," Applied and Environmental Microbiology, Vol. 75, No. 19, 2009, pp. 6132-6141. doi:10.1128/AEM.01187-09

[16] E. Palmqvist and B. Hahn-Hagerdal, "Fermentation of Lignocellulosic Hydrolysates II: Inhibitors and Mechanisms of Inhibition," Bioresource Technology, Vol. 74, No. 1, 2000, pp. 25-33. doi:10.1016/S0960-8524(99)00161-3

[17] O. Kandler and N. Weiss, "Regular, Nonsporing GramPositive Rods: Lactobacillus," In: P. H. A. Sneath, N. Mair, M. E. Sharpe and J. G. Holt, Eds., Bergey's Manual of Systematic Bacteriology, Williams \& Wilkins, Baltimore, Vol. 2, 1986, pp. 1209-1234.

[18] H. Hörhammer, O. Berezina, E. Hiltunen, T. Granström and A. van Heiningen, "Semi-Bleached Paper and Fermentation Products from a Larch Biorefinery," TAPPI Journal, Vol. 11, 2012, pp. 31-39.

[19] E. P. Knoshaug and M. Zhang, "Butanol Tolerance in a Selection of Microorganisms," Applied Biochemistry and Biotechnology, Vol. 153, No. 1-3, 2009, pp. 13-20. doi:10.1007/s12010-008-8460-4

[20] O. V. Berezina, S. P. Sineoky, G. A. Velikodvorskaya, W. H. Schwarz and V. V. Zverlov, "Extracellular Glycosyl Hydrolase Activity of the Clostridium Strains Producing Acetone, Butanol, and Ethanol," Applied Biochemistry and Microbiology, Vol. 44, 2008, pp. 42-47. doi:10.1134/S0003683808010079

[21] P. K. Smith, R. I. Krohn, G. T. Hermanson, A. K. Mallia, F. H. Gartner, M. D. Provenzano, E. K. Fujimoto, N. M. Goeke, B. J. Olson and D. C. Klenk, "Measurement of Protein Using Bicinchoninic Acid," Analytical Biochem- 
istry, Vol. 150, No. 1, 1985, pp. 76-85. doi:10.1016/0003-2697(85)90442-7

[22] M. M. Bradford, "A Rapid and Sensitive Method for the Quantification of Microgram Quantities of Protein Utilizing the Principle of Protein-Dye Binding," Analytical Biochemistry, Vol. 72, 1976, pp. 248-254. doi:10.1016/0003-2697(76)90527-3

[23] D. Kessler, I. Leibrecht and J. Knappe, "Pyruvate-Formate-Lyase-Deactivase and Acetyl-CoA Reductase Activities of Escherichia coli Reside on a Polymeric Protein Particle Encoded by adhE," FEBS Letters, Vol. 281, No. 1-2, 1991, pp. 59-63. doi:10.1016/0014-5793(91)80358-A

[24] M. G. Hartmanis and S. Gatenbeck, "Intermediary Metabolism in Clostridium acetobutylicum: Levels of Enzymes Involved in the Formation of Acetate and $\mathrm{Bu}-$ tyrate," Applied and Environmental Microbiology, Vol. 47, No. 6, 1984, pp. 1277-1283.

[25] A. Molina-Gutierrez, V. Stippl, A. Delgado, M. G. Ganzle and R. F. Vogel, "In Situ Determination of the Intracellular $\mathrm{pH}$ of Lactococcus lactis and Lactobacillus plantarum During Pressure Treatment," Applied and Environmental Microbiology, Vol. 68, No. 9, 2002, pp. 43994406. doi:10.1128/AEM.68.9.4399-4406.2002

[26] H. Yahui, L. Yan, H. Hongwu and Y. Junlin, “A New Optimized Spectrophotometric Assay for the Measurement of Pyruvate Dehydrogenase's Activity," The 1st International Conference on Bioinformatics and Biomedical Engineering, 2007.

[27] N. Asanuma, M. lwamoto and T. Hino, "Structure and Transcriptional Regulation of the Gene Encoding Pyruvate Formate-Lyase of a Ruminal Bacterium, Streptococcus bovis," Microbiology, Vol. 145, No. 1, 1999, pp. 151-157. doi:10.1099/13500872-145-1-151

[28] H. Taniai, K. Iida, M. Seki, M. Saito, S. Shiota, H. Nakayama and S. Yoshida, "Concerted Action of Lactate Oxidase and Pyruvate Oxidase in Aerobic Growth of Streptococcus pneumoniae: Role of Lactate as an Energy Source," Journal of Bacteriology, Vol. 190, No. 10, 2008, pp. 3572-3579. doi:10.1128/JB.01882-07

[29] T. C. Hoppner and H. W. Doelle, "Purification and Kinetic Characteristics of Pyruvate Decarboxylase and Ethanol Dehydrogenase from Zymomonas mobilis in Relation to Ethanol Production,"European Journal of Applied Microbiology and Biotechnology," Vol. 17, No. 3, 1983, pp. 152-157. doi:10.1007/BF00505880

[30] H. U. Bergmeyer, "Methoden der Enzymatischen Analyse," Verlag Chemie, Weinheim, 1970.

[31] W. de Koning and K. van Dam, "A Method for the Determination of Changes of Glycolytic Metabolites in Yeast on a Subsecond Time Scale Using Extraction at Neutral pH," Analytical Biochemistry, Vol. 204, No. 1, 1992, pp. 118-123. doi:10.1016/0003-2697(92)90149-2

[32] L. Axelsson, "Lactic Acid Bacteria: Classification and Physiology," In: S. Salminen and A. Wright, Eds., Lactic Acid Bacteria. Microbiology and Functional Aspects, 2nd Edition, Marcel Dekker Inc., New York, 1998, pp. 1-72.

[33] K. Makarova, A. Slesarev, Y. Wolf, A. Sorokin, et al., "Comparative Genomics of the Lactic Acid Bacteria," Proceedings of the National Academy of Sciences of the
United States of America, Vol. 103, No. 42, 2006, pp. 15611-15616. doi:10.1073/pnas.0607117103

[34] Y. Wang, K. J. Addess, J. Chen, L. Y. Geer, J. He, S. He, S. Lu, T. Madej, A. Marchler-Bauer, P. A. Thiessen, N. Zhang and S. H. Bryant, "MMDB: Annotating Protein Sequences with Entrez's 3D-structure Database," Nucleic Acids Research, Vol. 35, 2007, pp. 205-210. doi:10.1093/nar/gk1952

[35] S. Condon, "Responses of Lactic-Acid Bacteria to Oxygen," FEMS Microbiology Reviews, Vol. 46, No. 3, 1987, pp. 269-280. doi:10.1111/j.1574-6968.1987.tb02465.x

[36] A. Jänsch, S. Freiding, J. Behr and R. F. Vogel, "Contribution of the NADH-Oxidase (Nox) to the Aerobic Life of Lactobacillus sanfranciscensis DSM20451T," Food Microbiology, Vol. 28, No. 1, 2011, pp. 29-37. doi:10.1016/j.fm.2010.08.001

[37] C. A. Lucey and S. Condon, "Active Role of Oxygen and NADH Oxidase in Growth and Energy Metabolism of Leuconostoc," Journal of General Microbiology, Vol. 132, No. 7, 1986, pp. 1789-1796.

[38] R. W. Eltz and P. J. Vandemark, "Fructose Dissimilation of Lactobacillus brevis," Journal of Bacteriology, Vol. 79, No. 6, 1960, pp. 763-776.

[39] H. Richter, I. Hamann and G. Unden, "Use of the Mannitol Pathway in Fructose Fermentation of Oenococcus oeni due to Limiting Redox Regeneration Capacity of the Ethanol Pathway," Archives of Microbiology, Vol. 179, No. 4, 2003, pp. 227-233.

[40] I. L. Benito de Cardenas, O. V. Ledesma, A. A. Pesce de Ruiz Holgado and G. Oliver, "Effect of Lactate on the Growth and Production of Diacetyl and Acetoin by Lactobacilli," Journal of Dairy Science, Vol. 68, No. 8, 1985, pp. 1897-1901. doi:10.3168/jds.S0022-0302(85)81047-X

[41] M. G. Murphy, L. O'Connor, D. Walsh and S. Condon, "Oxygen Dependent Lactate Utilization by Lactobacillus plantarum," Archives of Microbiology, Vol. 141, No. 1, 1985, pp. 75-79. doi:10.1007/BF00446743

[42] P. Goffin, F. Lorquet, M. Kleerebezem and P. Hols, "Major Role of NAD-dependent Lactate Dehydrogenases in Aerobic Lactate Utilization in Lactobacillus plantarum during Early Stationary Phase," Journal of Bacteriology, Vol. 186, No. 19, 2004, pp. 6661-6666. doi:10.1128/JB.186.19.6661-6666.2004

[43] B. Sedewitz, K. H. Schleifer and F. Gotz, "Physiological Role of Pyruvate Oxidase in the Aerobic Metabolism of Lactobacillus plantarum," Journal of Bacteriology, Vol. 160, No. 1, 1984, pp. 462-465.

[44] F. Lorquet, P. Goffin, L. Muscariello, J. B. Baudry, V. Ladero, M. Sacco, M. Kleerebezem and P. Hols, "Characterization and Functional Analysis of the poxB gene, which Encodes Pyruvate Oxidase in Lactobacillus plantarum," Journal of Bacteriology, Vol. 186, No. 12, pp. 6661-6666.

[45] P. Goffin, L. Muscariello, F. Lorquet, A. Stukkens, D. Prozzi, M. Sacco, M. Kleerebezem and P. Hols, "Involvement of Pyruvate Oxidase Activity and Acetate Production in the Survival of Lactobacillus plantarum during the Stationary Phase of Aerobic Growth," Applied and Environmental Microbiology, Vol. 72, No. 12, 2006, 
pp. 7933-7940. doi:10.1128/AEM.00659-06

[46] T. D. Thomas and K. W. Turner, "Carbohydrate Fermentation by Streptococcus cremoris and Streptococcus lactis Growing in Agar Gels," Applied and Environmental Microbiology, Vol. 41, No. 6, 1981, pp. 1289-1294.

[47] S. Takahashi, K. Abbe and T. Yamada, "Purification of Pyruvate Formate-Lyase from Streptococcus mutans and its Regulatory Properties," Journal of Bacteriology, Vol. 149, No. 3, 1982, pp. 1034-1040.
[48] O. Kandler, "Carbohydrate Metabolism in Lactic Acid Bacteria," Antonie van Leeuwenhoek, Vol. 49, No. 3, 1983, pp. 209-224. doi:10.1007/BF00399499

[49] F. Li, J. Hinderberger, H. Seedorf, J. Zhang, W. Buckel and R. K. Thauer, "Coupled Ferredoxin and Crotonyl Coenzyme A (CoA) Reduction with NADH Catalyzed by the Butyryl-CoA Dehydrogenase/Etf Complex from Clostridium kluyveri," Journal of Bacteriology, Vol. 190, No. 3, 2008, pp. 843-850. doi:10.1128/JB.01417-07 